\title{
Hypopituitarism after Gamma Knife surgery for postoperative nonfunctioning pituitary adenoma
}

\author{
Ji Woong Oh, MD, ${ }^{1}$ Kyoung Su Sung, MD, ${ }^{2}$ Ju Hyung Moon, MD, ${ }^{3,4}$ Eui Hyun Kim, MD, PhD, ${ }^{3,4}$ \\ Won Seok Chang, MD, PhD, ${ }^{3}$ Hyun Ho Jung, MD, PhD, ${ }^{3}$ Jin Woo Chang, MD, PhD, ${ }^{3}$ \\ Yong Gou Park, MD, PhD, ${ }^{3}$ Sun Ho Kim, MD, PhD, ${ }^{3,4}$ and Jong Hee Chang, MD, PhD $3{ }^{3,4}$
}

\begin{abstract}
'Department of Neurosurgery, Yonsei University Wonju College of Medicine, Wonju; ${ }^{2}$ Department of Neurosurgery, Dong-A University College of Medicine, Busan; and ${ }^{3}$ Department of Neurosurgery, ${ }^{4}$ Brain Tumor Center, Yonsei University College of Medicine, Seoul, Korea
\end{abstract}

OBJECTIVE This study investigated long-term follow-up data on the combined pituitary function test (CPFT) in patients who had undergone transsphenoidal surgery (TSS) for nonfunctioning pituitary adenoma (NFPA) to determine the clinical parameters indicative of hypopituitarism following postoperative Gamma Knife surgery (GKS).

\begin{abstract}
METHODS Between 2001 and 2015, a total of 971 NFPA patients underwent TSS, and 76 of them (7.8\%) underwent postoperative GKS. All 76 patients were evaluated with a CPFT before and after GKS. The hormonal states were analyzed based on the following parameters: relevant factors before GKS (age, sex, extent of resection, pre-GKS hormonal states, time interval between TSS and GKS), GKS-related factors (tumor volume; radiation dose to tumor, pituitary stalk, and normal gland; distance between tumor and stalk), and clinical outcomes (tumor control rate, changes in hormonal states, need for hormone-related medication due to hormonal changes).

RESULTS Of the 971 NFPA patients, 797 had gross-total resection (GTR) and 174 had subtotal resection (STR). Twenty-five GTR patients (3.1\%) and 51 STR patients (29.3\%) underwent GKS. The average follow-up period after GKS was $53.5 \pm 35.5$ months, and the tumor control rate was $96 \%$. Of the 76 patients who underwent GKS, 23 were excluded due to pre-GKS panhypopituitarism (22) or loss to follow-up (1). Hypopituitarism developed in $13(24.5 \%)$ of the remaining 53 patients after GKS. A higher incidence of post-GKS hypopituitarism occurred in the patients with normal pre-GKS hormonal states $(41.7 \%, 10 / 24)$ than in the patients with abnormal pre-GKS hormonal states $(10.3 \%, 3 / 29 ; p=0.024)$. Target tumor volume $\left(4.7 \pm 3.9 \mathrm{~cm}^{3}\right)$, distance between tumor and pituitary stalk $(2.0 \pm 2.2 \mathrm{~mm})$, stalk dose (cutoffs: mean dose $7.56 \mathrm{~Gy}$, maximal dose $12.3 \mathrm{~Gy}$ ), and normal gland dose (cutoffs: maximal dose $13.9 \mathrm{~Gy}$, minimal dose $5.25 \mathrm{~Gy}$ ) were factors predictive of post-GKS hypopituitarism $(p<0.05)$.
\end{abstract}

CONCLUSIONS This study analyzed the long-term follow-up CPFT data on hormonal changes in NFPA patients who underwent GKS after TSS. The authors propose a cutoff value for the radiation dose to the pituitary stalk and normal gland for the prevention of post-GKS hypopituitarism.

https://thejns.org/doi/abs/10.3171/2018.7.GKS181589

KEYWORDS Gamma Knife surgery; pituitary adenoma; hypopituitarism; pituitary surgery; stereotactic radiosurgery

$\mathrm{N}$ ONFUNCTIONING pituitary adenomas (NFPAs) make up about $15 \%-30 \%$ of all pituitary adenomas. ${ }^{2,4}$ Even if a complete tumor resection is performed by an experienced surgeon, the recurrence rate is $20 \%-$ $40 \%$ with diverse clinical symptoms. ${ }^{9,15}$ Hence, additional Gamma Knife surgery (GKS) is widely performed not only after subtotal removal, but also after total tumor resection if there is evidence of tumor recurrence. The radiosurgical procedure is a less invasive treatment; however, there is a risk of hypopituitarism following treatment. Not much has been reported on post-GKS hypopituitarism after transsphenoidal surgery (TSS) in the context of an analysis based on long-term combined pituitary function test (CPFT) data on abnormal states of the hormonal axis. In this regard, we present a large cohort study of patients with reasonably long-term endocrine and radiographic follow-up in order to provide a better understanding of the risks of hypopituitarism resulting from GKS.

ABBREVIATIONS CPFT = combined pituitary function test; GKS = Gamma Knife surgery; GTR = gross-total resection; NFPA = nonfunctioning pituitary adenoma; ROC = receiver operating characteristic; STR = subtotal resection; TSS = transsphenoidal surgery.

SUBMITTED June 1, 2018. ACCEPTED July 24, 2018.

INCLUDE WHEN CITING DOI: 10.3171/2018.7.GKS181589. 


\section{Methods \\ Patient Population}

Between 2001 and 2015, a total of 971 NFPA patients underwent TSS, and 76 of them (7.8\%) underwent postoperative GKS. All 76 patients had comprehensive endocrine evaluations such as CPFT prior to GKS in order to assess the state of each hormonal axis. Post-GKS hypopituitarism was defined as any abnormal CPFT data on a post-GKS hormonal axis relative to its pre-GKS status regardless of the presence of subclinical symptoms or the need for hormone-related medication. All patients were evaluated based on the following parameters: pre-GKSrelated factors (patient age and sex, extent of resection, pre-GKS hormonal states, time interval between TSS and GKS), GKS-related factors (tumor volume; radiation dose to tumor, pituitary stalk, and normal gland; distance between tumor and pituitary stalk), and clinical outcomes (tumor control rate, changes in hormonal states, need for hormone-related medication due to hormonal changes).

\section{Combined Pituitary Function Test}

We evaluated changes in hormonal function via the CPFT, which was performed before and between 6 and 12 months after GKS. The medical follow-up including CPFT in all patients was conducted by a team consisting of neurosurgeons and pituitary endocrinologists every 1 or 2 years to observe any changes in hormonal function. The protocols for CPFT have been reported by $\mathrm{Ku}$ et al., ${ }^{6}$ and the results of testing were confirmed by two endocrinologists. Briefly, a subject was injected with $0.1 \mathrm{U} / \mathrm{kg}$ of regular insulin, $500 \mathrm{mg}$ of thyrotropin-releasing hormone, and $100 \mathrm{mg}$ of luteinizing hormone-releasing hormone. Then, the patient's level of growth hormone (GH), cortisol, adrenocorticotropic hormone (ACTH), prolactin (PRL), thyroid-stimulating hormone (TSH), luteinizing hormone (LH), and follicle-stimulating hormone (FSH) were analyzed. For the test of appropriate stress induction, the level of nadir glucose was set below $40 \mathrm{mmol} / \mathrm{L}$ for the nondiabetic patients, while it was set below $50 \%$ of the basal glucose for the diabetic patients. Levels of GH, cortisol, and ACTH were checked from the blood sampling at $0,30,60,90$, and 120 minutes from the injection, whereas PRL, TSH, FSH, and LH were checked at 0,15 , 30,60 , and 120 minutes. The criteria for normal responses were as follows: peak $\mathrm{GH},>3 \mathrm{ng} / \mathrm{ml}$; peak cortisol, $>180$ $\mathrm{ng} / \mathrm{ml}$ or $>70 \mathrm{ng} / \mathrm{ml}$ increase compared with the basal level; basal PRL, 2-15 $\mathrm{ng} / \mathrm{ml}$ and peak PRL, more than twice the basal PRL; peak TSH, > $5 \mathrm{mIU} / \mathrm{ml}$ compared with the basal level while free thyroxine was within the normal range; peak FSH, $>2 \mathrm{mIU} / \mathrm{ml}$ compared with the basal level; and peak $\mathrm{LH},>10 \mathrm{mIU} / \mathrm{ml}$ compared with the basal level. Elevated basal gonadotropin levels in postmenopausal patients and no menstrual disorders in premenopausal patients were regarded as abnormal. When an abnormal state of the hormonal axis was observed, we defined it as the new onset of hypopituitarism.

\section{Gamma Knife Surgery}

The primary treatment policy for NFPA is TSS at our institution. Definitions of subtotal resection (STR) and gross-total resection (GTR) are based on both the MRI findings and the surgeon's intraoperative visual confirmation. All postoperative MRI studies were performed within 1 or 2 days after surgery. If remnant tumors were not detected through the dynamic MRI view with contrast studies, then the surgery was confirmed to be GTR. All cases of STR and GTR are evaluated with MRI follow-up every 1 or 2 years after surgery. If progression of a remnant mass is observed in patients after their first STR, the disease is treated with GKS according to our treatment protocol. However, early postoperative adjuvant GKS can be considered under certain circumstances such as in a patient with a poor medical condition and/or a remnant mass location near critical structures (e.g., optic nerve) where the feasibility of GKS cannot be guaranteed when tumor progression occurs. If a tumor recurrence appears after the first GTR, the treatment of choice is also GKS. Moreover, GKS is indicated as the first treatment choice when surgical removal of a tumor is judged to be difficult due to a poor patient condition, the nature of the tumor, and a tumor location where the main mass is not adjacent to the pituitary stalk or optic nerve. For instance, if the main mass is within $3 \mathrm{~mm}$ of the optic nerve, surgical removal of the mass is preferred as such cases are generally recognized to be unsuitable for GKS.

\section{Radiosurgical Procedure}

Briefly, the Leksell head frame was placed with the patient under local anesthesia, and thin-sliced noncontrast T1-weighted MRI as well as Gd-enhanced T1- and T2weighted MRI sequences were obtained in all patients. The treatment was performed using the Leksell Gamma Knife model C type between 2001 and 2009, which was replaced with the Perfexion model thereafter (both Elekta). Dose planning was performed by a team of neurosurgeons expert in TSS, neurosurgeons expert in GKS, and medical physicists. The mean target volume of pituitary adenoma was $3.69 \pm 3.30 \mathrm{~cm}^{3}$. Our mean prescription isodose line for GKS was $49.9 \% \pm 0.14 \%$. Additionally, the prescription dose and maximum radiation dose were 14.20 \pm 1.34 Gy and $23 \mathrm{~Gy}$, respectively. We used 4-mm and $8-\mathrm{mm}$ collimators, and the average number of isocenters was $21.9 \pm 11.3$.

\section{Dose Calculation}

GammaPlan system software (version 5.31, Elekta Perfexion) was used to select and draw the regions of the entire pituitary stalk and normal gland. Then, the software's histogram function was applied to calculate the radiation dose to the stalk and normal gland. With the same method, volumetric information on the pituitary stalk and the tumor mass was also obtained. It was not difficult to identify the pituitary stalk on the MRI studies even after the TSS. However, outlining the margins of the post-TSS normal gland was rather challenging. In the latter case, the dose calculation was made based on the outlining of the normal gland at the diaphragm level. The mean dose, maximal dose, and minimal dose to the pituitary stalk and the normal gland were calculated according to the aforementioned method. The whole surface area of the pitu- 
itary stalk was divided into 4-, 6-, 8-, 10-, and 12-Gy circle lines in order to calculate the area percentage of the stalk. For instance, area percentage $>4$ Gy means the proportion of the stalk with a radiation dose greater than $4 \mathrm{~Gy}$.

\section{Statistical Analysis}

All studies were statistically analyzed using IBM SPSS version 23 (IBM Corp.), and the graphic data were made using GraphPad Prism 5.03 (GraphPad Software Inc.). Continuous variables are presented as the means and standard deviations, whereas categorical variables are presented as frequencies and percentages. An independent t-test was used to compare the continuous variables of the two groups (hypopituitarism vs none). A chi-square test was used to compare the nominal factors of the two groups. The receiver operating characteristic (ROC) curve was used to measure sensitivity and specificity. The cutoff value for the ROC curve was obtained using MEDCALC (MedCalc Software). Statistical significance was confirmed when the $\mathrm{p}$ value was $<0.05$.

\section{Results}

\section{Incidence and Time Interval of GKS After TSS}

Of the 971 NFPA patients who underwent tumor removal via TSS, a GTR was performed in 797 patients, while an STR was conducted in the remaining 174 patients. Gamma Knife surgery was performed in 25 patients $(3.1 \%)$ in the GTR group, compared to 51 patients $(29.3 \%)$ in the STR group, and the higher chance of GKS in the STR group was statistically significant $(\mathrm{p}=0.000$; Fig. 1). Furthermore, the time interval between TSS and GKS was $91.6 \pm 42.7$ months in the GTR group and 40.2 \pm 31.1 months in the STR group. This finding was also statistically significant $(\mathrm{p}=0.000)$.

\section{Hypopituitarism After GKS}

The average follow-up period after GKS was $53.5 \pm$ 35.5 months, and the overall tumor control rate was $96 \%$. Of the 76 patients who had undergone GKS, we analyzed the CPFT data for 53 patients since we had to exclude 22 patients with panhypopituitarism after TSS and 1 patient lost to follow-up. Hypopituitarism developed in 13 $(24.5 \%)$ of these 53 patients. A higher incidence of postGKS hypopituitarism occurred in the patients with normal pre-GKS hormonal states $(41.7 \%, 10 / 24)$ than in those with abnormal pre-GKS hormonal states $(10.3 \%, 3 / 29 ; \mathrm{p}=$ 0.024; Fig. 2). We investigated the hormonal axis function of the 13 patients with post-GKS hypopituitarism based on their CPFT data. We found a total of 27 abnormal axes: somatotroph $(n=9,33.3 \%)$, lactotroph $(n=4,14.8 \%)$, corticotroph $(\mathrm{n}=5,18.5 \%)$, gonadotroph $(\mathrm{n}=3,11.1 \%)$, and thyrotroph ( $n=6,22.2 \%$; Fig. 3). Most of the 13 patients with hypopituitarism were asymptomatic, and only 4 patients $(7.5 \%)$ required hormone-related medications. In a hormonal axis analysis, the hypopituitarism patients with an abnormal axis involving thyrotroph $(\mathrm{n}=3,50 \%)$, corticotroph $(\mathrm{n}=2,40 \%)$, and gonadotroph $(\mathrm{n}=1,33.3 \%)$ received prescription medication. Meanwhile, it is notable that the hormone-related medication was not necessary in the abnormal axis cases involving lactotroph and somato-
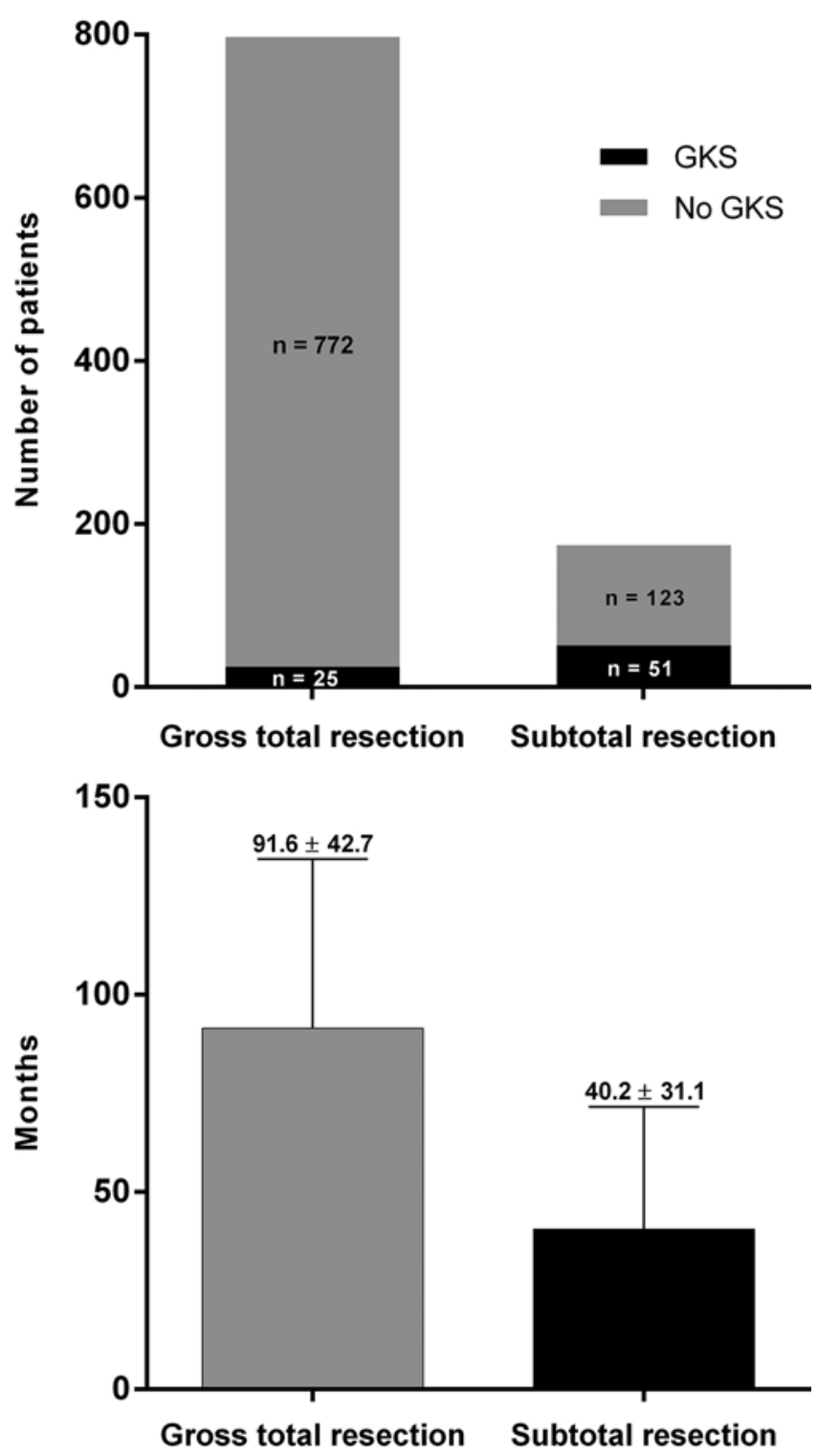

FIG. 1. Graphs showing the incidence of postoperative adjuvant GKS in NFPA patients and the interval between TSS and GKS. Patients who underwent STR of a tumor mass had a higher chance of undergoing GKS (29.3\%) than those who underwent GTR (3.1\%; $p=0.000$; upper) Patients in the GTR group had a longer time interval between TSS and GKS than those in the STR group $(91.6 \pm 42.7$ months vs $40.2 \pm 31.1$ months, respectively, $p=0.000$; lower).

troph. Nonetheless, the probability of taking medication after hypopituitarism based on the hormonal axis analysis was not statistically significant $(\mathrm{p}=0.11)$.

\section{Radiosurgical Parameters of the Pituitary Stalk and Normal Gland}

Firstly, the target tumor volume was larger in the patient group with hypopituitarism $\left(4.7 \pm 3.9 \mathrm{~cm}^{3}\right)$ than in those without $\left(2.85 \pm 2.7 \mathrm{~cm}^{3}\right)$, and the difference was statistically meaningful $(\mathrm{p}=0.048$; Table 1$)$. However, there was no difference in the tumor radiation dose between the two groups. According to the radiosurgical parameters, 


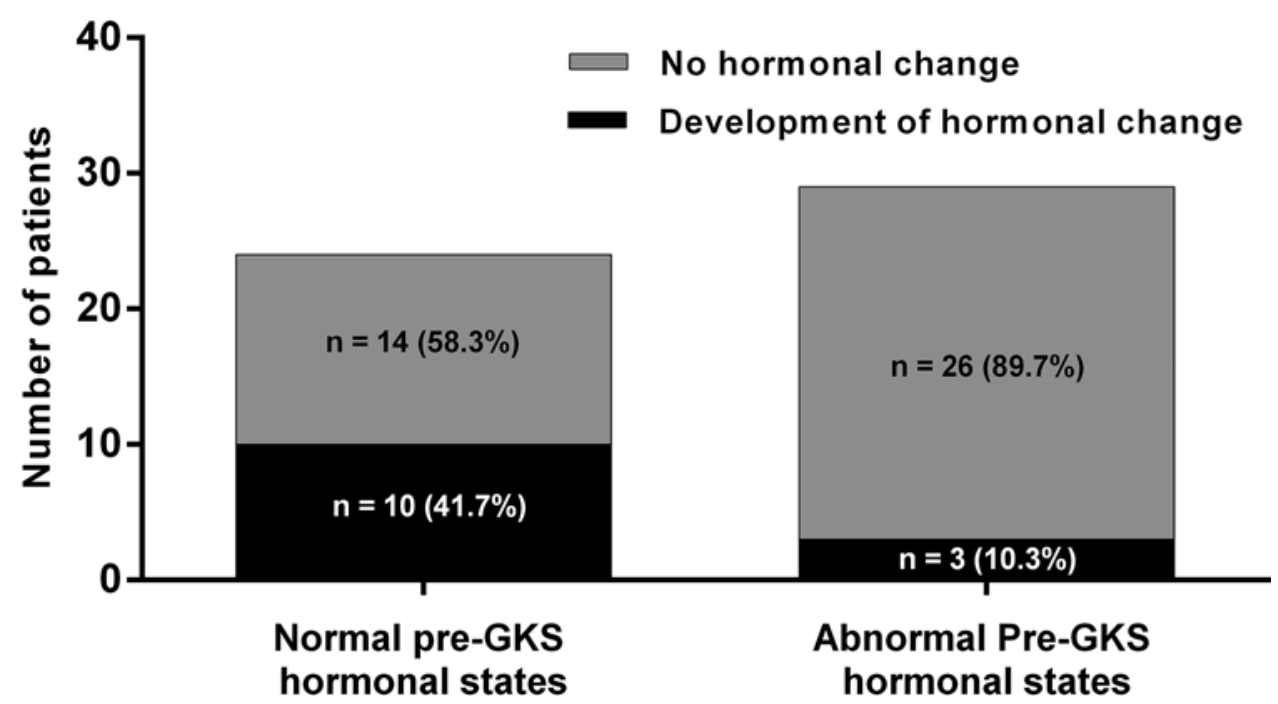

FIG. 2. Patterns in the development of hormonal changes based on the pre-GKS hormonal states. Hormonal changes were observed more frequently in the patients with a normal pre-GKS hormonal state than in those with an abnormal pre-GKS hormonal state $(41.7 \%$ vs $10.3 \%, p=0.024)$.

the distance between the pituitary stalk and the tumor was much shorter in the patients with hypopituitarism than in those without, and this further determined the statistically

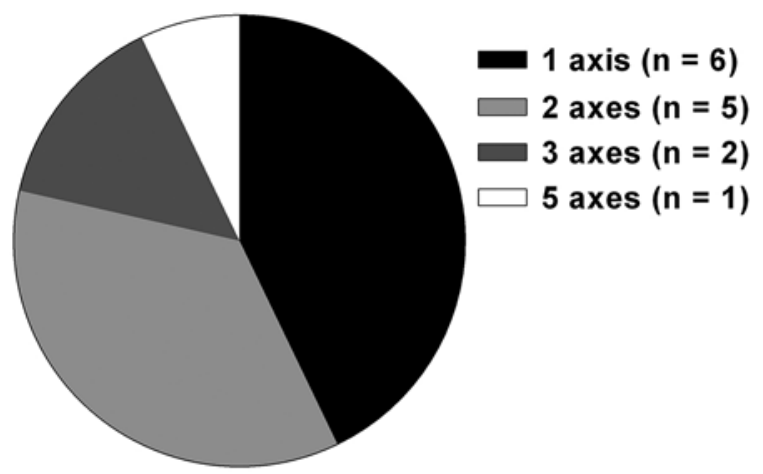

Numbers of hormonal axes

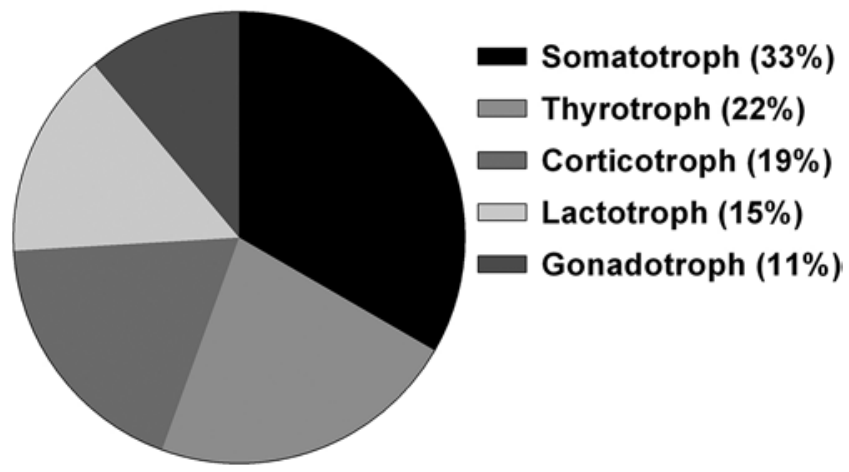

Types of hormonal axes

FIG. 3. Incidence of hypopituitarism based on the number of abnormal axes and on the types of hormonal axes. Most GKS-related hypopituitarism occurred in one or two axes (upper). Among them, the somatotroph axis showed the highest incidence rate of hypopituitarism (lower). However, the proportional difference among the axes was not statistically significant. significant differences in the mean and maximal doses to the pituitary stalk $(\mathrm{p}<0.05)$. Nonetheless, the minimal dose was not statistically significant. On the other hand, the mean radiation dose to the normal gland did not show any significant difference between the groups, whereas the maximal dose and minimal dose showed statistically significant differences $(\mathrm{p}<0.05)$. In terms of the proportion of radiation to the stalk, there was a statistical difference between the two groups in the areas with more than $6 \mathrm{~Gy}$ and those with more than 8 Gy (Table 2).

By using the ROC curve, we determined the cutoff values for the mean and maximal radiation doses to the stalk and the maximal and minimal radiation doses to the normal gland between the groups with and without hypopituitarism (Fig. 4). When the cutoff values for the mean and maximal doses to the stalk were set as $7.56 \mathrm{~Gy}$ and $12.3 \mathrm{~Gy}$, respectively, the sensitivity was $76.9 \%$ for both doses, while the specificities were $69.2 \%$ and $69.2 \%$, respectively. When the cutoff values for the maximal and minimal doses to the normal gland were set as $13.9 \mathrm{~Gy}$ and $5.25 \mathrm{~Gy}$, respectively, the sensitivities were $76.9 \%$ and $84.6 \%$, whereas the specificities were $61.5 \%$ and $65.8 \%$, respectively. We drew the ROC curve based on the area percentage of 6 and $8 \mathrm{~Gy}$, and we calculated the sensitivity and specificity. When the cutoff value for area percentage was set as $74.50 \%$, the sensitivity and specificity were $76.9 \%$ and $71.8 \%$, respectively. On the contrary, when we set the cutoff value for area percentage with 8 Gy as $21 \%$, the sensitivity and specificity were $84.6 \%$ and $59.0 \%$, respectively.

\section{Discussion}

In this study we investigated the incidence of hypopituitarism after adjuvant post-TSS GKS in patients with NFPA based on their long-term follow-up CPFT data showing abnormal hormonal axis functions. We also evaluated the postradiosurgical outcomes of the patients based 
TABLE 1. Radiosurgical parameters and hypopituitarism

\begin{tabular}{|c|c|c|c|}
\hline \multirow[b]{2}{*}{ Parameter } & \multicolumn{2}{|c|}{$\begin{array}{c}\text { Post-GKS } \\
\text { Hypopituitarism }\end{array}$} & \multirow[b]{2}{*}{$\begin{array}{c}p \\
\text { Value }\end{array}$} \\
\hline & $\begin{array}{c}\text { Yes } \\
(n=13)\end{array}$ & $\begin{array}{c}\text { No } \\
(n=40)\end{array}$ & \\
\hline \multicolumn{4}{|l|}{ Target tumor } \\
\hline Vol $\left(\mathrm{cm}^{3}\right)$ & $4.7 \pm 3.9$ & $2.85 \pm 2.7$ & $0.048^{*}$ \\
\hline Mean dose (Gy) & $20.6 \pm 0.7$ & $20.6 \pm 1.9$ & 0.909 \\
\hline Max dose (Gy) & $28.1 \pm 0.6$ & $28.3 \pm 1.7$ & 0.764 \\
\hline \multicolumn{4}{|l|}{ Pituitary stalk } \\
\hline Mean dose (Gy) & $9.4 \pm 4.1$ & $6.7 \pm 4.0$ & $0.036^{*}$ \\
\hline Max dose (Gy) & $15.6 \pm 6.6$ & $10.6 \pm 5.5$ & $0.010^{*}$ \\
\hline Min dose (Gy) & $4.7 \pm 1.9$ & $3.7 \pm 2.7$ & 0.249 \\
\hline Distance btwn tumor \& stalk (mm) & $2.0 \pm 2.2$ & $4.5 \pm 3.4$ & $0.005^{*}$ \\
\hline \multicolumn{4}{|l|}{ Normal gland } \\
\hline Mean dose (Gy) & $14.1 \pm 7.0$ & $7.9 \pm 5.7$ & 0.170 \\
\hline Max dose (Gy) & $18.6 \pm 6.5$ & $11.4 \pm 6.6$ & $0.003^{*}$ \\
\hline Min dose (Gy) & $10.9 \pm 7.1$ & $5.1 \pm 4.1$ & $0.015^{*}$ \\
\hline
\end{tabular}

$\mathrm{n}=$ number of patients.

Values are shown as the mean \pm standard deviation unless otherwise indicated.

* Statistical significance with a p value $<0.05$

on the time of GKS indication. Thus, we found that postGKS hypopituitarism was associated with the mean tumor volume and the mean radiation dose to the stalk, whereas it was associated with the maximal and minimal doses to the normal gland.

Traditionally, conventional fractionated radiotherapy was chosen to treat residual tumor and recurrence. However, it has been reported to result in long-term pituitary hormonal deficiency in 50\%-100\% of treated patients as well as a high complication rate; hence, the trend in treatment is changing toward radiosurgery rather than radiotherapy. ${ }^{11-13,19}$ As many have reported, GKS is well known to be effective additional therapy after TSS.1,17,18

Most TSS is performed to treat benign tumors, and the tumor control rate with GKS is known to be efficient; thus, the real concern of primary physicians is the minimization of complications. The most common complications of GKS are optic neuropathy and hypopituitarism. Depending on the individual neurosurgeon's operative policy and skills, the remnant adenoma is often localized around the cavernous sinus rather than the optic nerve during TSS. And, if the tumor recurrence is observed near the optic nerve, a secondary operation is preferred to radiosurgery. Moreover, many surgeons already have vast experience with GKS near the optic nerve in the context of other tumors, such as sphenoid wing meningioma; thus, it is rather rare to encounter an unexpected post-GKS optic neuropathy as a complication. The TSS protocol at our institution includes maximal removal of the tumor mass with capsulectomy, and if the tumor recurrence is near the optic nerve, a secondary operation is usually recommended to the patients; therefore, we excluded optic neuropathy as a radiation complication in this study.

Hormonal deficiency is usually caused by direct radia-
TABLE 2. Radiated proportion of whole pituitary stalk

\begin{tabular}{cccc}
\hline \multirow{2}{*}{$\begin{array}{c}\text { Radiation } \\
\text { to Stalk }\end{array}$} & $\begin{array}{c}\text { Hypopituitarism } \\
(\mathrm{n}=13)\end{array}$ & $\begin{array}{c}\text { No Hypopituitarism } \\
(\mathrm{n}=40)\end{array}$ & $\begin{array}{c}\mathrm{p} \\
\text { Value }\end{array}$ \\
\hline >4 Gy & $79.2 \pm 3.9$ & $63.8 \pm 40.6$ & 0.225 \\
\hline$>6$ Gy & $75.0 \pm 64.7$ & $44.2 \pm 41.49$ & $0.021^{*}$ \\
\hline$>8$ Gy & $55.0 \pm 34.7$ & $30.2 \pm 38.6$ & $0.045^{*}$ \\
\hline$>10$ Gy & $36.5 \pm 32.9$ & $20.1 \pm 30.9$ & 0.110 \\
\hline$>12$ Gy & $22.9 \pm 30.6$ & $10.3 \pm 21.8$ & 0.109 \\
\hline
\end{tabular}

Values are shown as the mean \pm standard deviation unless otherwise indicated.

${ }^{*}$ Statistical significance with a $p$ value $<0.05$.

tion to the pituitary stalk and normal gland. Structurally, the stalk and normal glands are close to each other; thus, by the time of GKS treatment, injury to normal tissue is unavoidable given the initial mass effect of the tumor and surgical manipulation of the mass as well as the radiation in the adjacent tissue potentially causing overall changes in the hormonal states. Knowing this, we attempted to analyze in depth the clinical and subclinical hormonal changes after postoperative GKS, and CPFT was a useful tool to evaluate the in situ hormonal states of the patients. Although CPFT is an invasive diagnostic tool, it is very powerful in evaluating the whole hormonal axis most accurately. At our institution, CPFT was conducted on an outpatient clinic basis. Imaging information on the normal structures within the radiation field is not sufficient to predict the hormonal complications after GKS. With MRI information only, one cannot compartmentalize the different hormone-producing regions. Therefore, it is imperative to monitor and evaluate the entire hormonal axis in order to understand the hormonal states of individual patients after GKS. Basal hormonal study alone is inadequate as one can miss the subclinical hormonal changes; thus, our institutional protocol for the post-GKS followup always includes CPFT. Other reports have been based on the basal hormonal studies alone, whereas in our study we analyzed the risks of post-GKS hypopituitarism in depth. $3,5,8,10,14$

One of the major factors in causing new-onset hormonal changes after GKS is the radiation dose. The main organs related to hormonal changes in the patients with NFPA include the hypothalamus, pituitary stalk, and normal gland. Subjects in the present study were patients who initially underwent TSS. When these patients underwent GKS, it was very rare for the radiation to affect the hypothalamus; therefore, we excluded the radiation dose to hypothalamus in our analysis. In many studies, the tumor margin dose was approximately 12-16 Gy, and the complication of hypopituitarism was reported to be $0 \%-40 \%$ of the overall cases. ${ }^{7,16,17,20}$ However, one must be careful in interpreting the data as the previous studies included both surgical and nonsurgical groups of patients with NFPA, as well as both functional and nonfunctioning tumors, and hormonal tests checked only the basal serum level.

We restricted the patient sample in our study to those with NFPA after TSS in order to find the factors related to newly developed hypopituitarism after postoperative GKS 

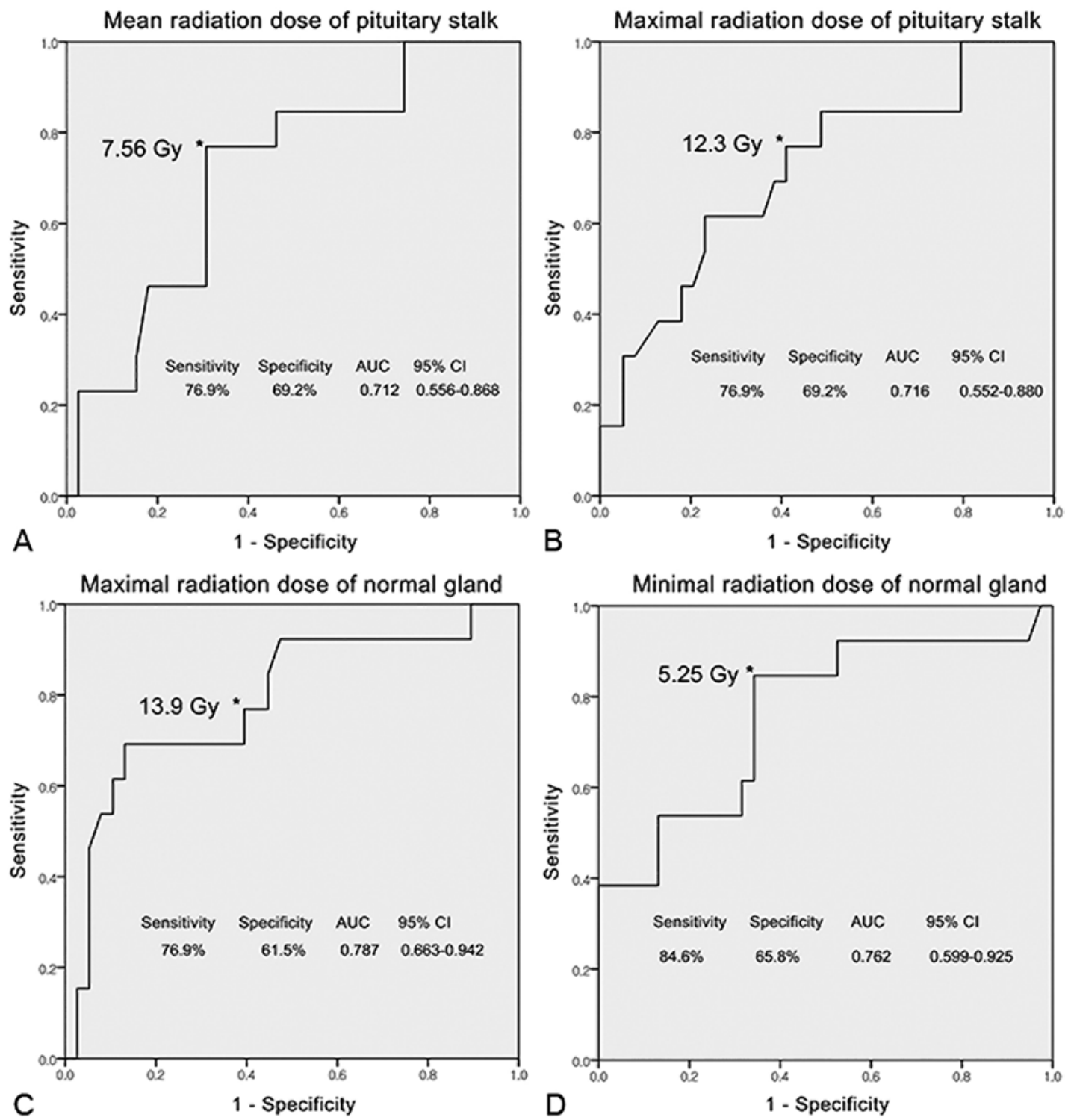

FIG. 4. Sensitivity and specificity analysis using the cutoff values for radiation dose to the pituitary stalk and normal gland. Various cutoff values for the radiation dose were used to investigate the incidence of hypopituitarism. The ROC curve of mean $(\mathbf{A})$ and maximal (B) radiation doses to the pituitary stalk. The ROC curve of maximal (C) and minimal (D) doses to normal gland. AUC = area under the curve; $\mathrm{Cl}=$ confidence interval.

based on a correlative analysis of long-term follow-up data on CPFT and radiation doses to the pituitary stalk and normal gland. Xu et al. ${ }^{21}$ reported on the importance of tumor margin dose when analyzing hypopituitarism after stereotactic radiosurgery. In contrast, Liscák et al. ${ }^{7}$ reported that morbidity was not related to the tumor margin dose as a higher radiation dose showed no clinical difference. One of the reasons for these conflicting reports is that, in NFPA, radiation doses to the pituitary stalk and normal gland, rather than the radiation dose to the tumor volume, affect the hormonal states of the patients. Thus, the tumor margin dose is only meaningful when it is correlated with the radiation dose to the tumor control area and adjacent structures. In the present study, we emphasized the importance of accurate calculation of radiation dose to the pituitary stalk and the normal gland. The spot dosimetry is useful in terms of measuring the radiation dose, yet we included the whole surface area of normal structures to accurately calculate the radiation dose in order to obtain the sensitivity and specificity for hypopituitarism. Because the subjects of our study were all patients who underwent TSS, it is not definite that all the normal glands were identified and included, whereas the stalk was easily identified so we could analyze it in all cases.

The key points of our study are as follows: 1) We have long-term follow-up data on CPFT for hormonal studies. 2) Our institution is a tertiary care center with specialization for pituitary adenoma; thus, all patients went through the systematized surgical, radiosurgical, and endocrinological evaluations and follow-up plans. 3) Our radiation dose cal- 
culation process outlined the maximal areas of stalk and normal gland in order to accurately measure sensitivity and specificity.

Pomeraniec et al..$^{14}$ reported that early GKS improves the outcomes of NFPA patients. However, one must consider the institutional difference in surgical policies in treating the pituitary tumors. For example, we only performed early GKS in cases of surgically difficult tumors or remnant tumors located near the optic nerve as GKS is not feasible when the tumor recurs. In most of the remaining cases, maximal tumor removal was conducted and GKS was considered only if tumor progression was noted during the long-term follow-up. Thus, 174 patients underwent STR and 123 of them did not require GKS; hence, the remaining 51 patients (29.3\%) did undergo GKS. Given this result, we questioned the appropriate timing of GKS for a remnant tumor mass. In this regard, we hypothesized that it would be better to perform GKS when the tumor was seen to become larger during the follow-up period if the therapeutic outcome were similar as some of the patients with remnant tumor did not require GKS. This result further led us to analyze the optimal timing of GKS for residual tumor after TSS. We divided the 51 STR patients into two subgroups: the group that underwent GKS within 6 months after TSS was defined as the early group, and the group that underwent GKS after 6 months during the follow-up period was defined as the late group. Then, we compared the tumor control rate and post-GKS hormonal deficiency between these two groups. We found that there was no statistically significant difference in the tumor control rate and the incidence of hormonal deficiency. However, we had only 5 cases in the early GKS group, and this imposed a limitation in the statistical analysis. Thus, it was difficult to recommend the optimal timing for GKS after TSS.

Another parameter that we must consider when discussing the appropriate timing of GKS for postoperative residual tumor is the distance between the tumor and the pituitary stalk. In cases of late GKS, we were concerned that a decrease in the distance between the stalk and the tumor could be due to tumor regrowth. In fact, immediate measurement of the postoperative distance between the stalk and the remnant tumor was $14.02 \pm 7.32 \mathrm{~mm}$ according to our data. However, this distance was reduced to 4.01 $\pm 3.46 \mathrm{~mm}$ when it was measured at the time of GKS. This decrease in the distance was not due to tumor regrowth, but rather to restoration of the stalk toward the midline in most cases. This requires further study as it is worthwhile to carefully evaluate when to decide on early or late GKS for the remnant tumor because one cannot neglect this phenomenon of the recovery of the stalk to its normal location in the brain.

A limitation of our study is the small number of cases and the possibility of a selection bias. Moreover, the study consists of retrospective data from a single institution; hence, it is inevitable to consider the surgical policy of the surgeon when interpreting the data. It is also worthwhile to note that, despite our best efforts in using the GammaPlan software, there was difficulty in calculating the whole area of normal gland due to the postsurgical change. Lastly, the timing of post-TSS GKS was not always the same in all patients, and this also represents a limitation to this study.

\section{Conclusions}

The overall rate of hypopituitarism after GKS for NFPA was $24.5 \%$. In order to reduce the incidence of hypopituitarism, we suggest a safe radiation dose protocol for the stalk (cutoffs: mean dose $7.56 \mathrm{~Gy}$, maximal dose $12.3 \mathrm{~Gy}$ ) and normal gland (cutoffs: maximal dose $13.9 \mathrm{~Gy}$, minimal dose 5.25 Gy). Given our data, we believe that we will be able to reduce the incidence of post-radiation-induced hypopituitarism.

\section{Acknowledgments}

This study was supported by the Basic Science Research Program through the National Research Foundation of Korea (NRF) funded by the Ministry of Education (NRF-2014R1A1A2058058).

\section{References}

1. Choi JY, Chang JH, Chang JW, Ha Y, Park YG, Chung SS: Radiological and hormonal responses of functioning pituitary adenomas after gamma knife radiosurgery. Yonsei Med J 44:602-607, 2003

2. Daly AF, Rixhon M, Adam C, Dempegioti A, Tichomirowa MA, Beckers A: High prevalence of pituitary adenomas: a cross-sectional study in the province of Liege, Belgium. J Clin Endocrinol Metab 91:4769-4775, 2006

3. El-Shehaby AM, Reda WA, Tawadros SR, Abdel Karim KM: Low-dose Gamma Knife surgery for nonfunctioning pituitary adenomas. J Neurosurg 117 Suppl:84-88, 2012

4. Ezzat S, Asa SL, Couldwell WT, Barr CE, Dodge WE, Vance ML, et al: The prevalence of pituitary adenomas: a systematic review. Cancer 101:613-619, 2004

5. Feigl GC, Pistracher K, Berghold A, Mokry M: Pituitary insufficiency as a side effect after radiosurgery for pituitary adenomas: the role of the hypothalamus. J Neurosurg $\mathbf{1 1 3}$ Suppl:153-159, 2010

6. Ku CR, Kim EH, Oh MC, Lee EJ, Kim SH: Surgical and endocrinological outcomes in the treatment of growth hormone-secreting pituitary adenomas according to the shift of surgical paradigm. Neurosurgery 71 (2 Suppl Operative):ons192-ons203, 2012

7. Liscák R, Vladyka V, Marek J, Simonová G, Vymazal J: Gamma knife radiosurgery for endocrine-inactive pituitary adenomas. Acta Neurochir (Wien) 149:999-1006, 2007

8. Losa M, Valle M, Mortini P, Franzin A, da Passano CF, Cenzato M, et al: Gamma knife surgery for treatment of residual nonfunctioning pituitary adenomas after surgical debulking. J Neurosurg 100:438-444, 2004

9. Marcou Y, Plowman PN: Stereotactic radiosurgery for pituitary adenomas. Trends Endocrinol Metab 11:132-137, 2000

10. Marek J, Jezková J, Hána V, Krsek M, Bandúrová L, Pecen L, et al: Is it possible to avoid hypopituitarism after irradiation of pituitary adenomas by the Leksell gamma knife? Eur J Endocrinol 164:169-178, 2011

11. McCord MW, Buatti JM, Fennell EM, Mendenhall WM, Marcus RB Jr, Rhoton AL, et al: Radiotherapy for pituitary adenoma: long-term outcome and sequelae. Int J Radiat Oncol Biol Phys 39:437-444, 1997

12. Milker-Zabel S, Debus J, Thilmann C, Schlegel W, Wannenmacher M: Fractionated stereotactically guided radiotherapy and radiosurgery in the treatment of functional and nonfunctional adenomas of the pituitary gland. Int J Radiat Oncol Biol Phys 50:1279-1286, 2001

13. Paek SH, Downes MB, Bednarz G, Keane WM, WernerWasik M, Curran WJ Jr, et al: Integration of surgery with fractionated stereotactic radiotherapy for treatment of nonfunctioning pituitary macroadenomas. Int J Radiat Oncol Biol Phys 61:795-808, 2005 
14. Pomeraniec IJ, Dallapiazza RF, Xu Z, Jane JA Jr, Sheehan JP: Early versus late Gamma Knife radiosurgery following transsphenoidal resection for nonfunctioning pituitary macroadenomas: a matched cohort study. J Neurosurg 125:202212,2016

15. Roelfsema F, Biermasz NR, Pereira AM: Clinical factors involved in the recurrence of pituitary adenomas after surgical remission: a structured review and meta-analysis. Pituitary 15:71-83, 2012

16. Sadik ZHA, Voormolen EHJ, Depauw PRAM, Burhani B, Nieuwlaat WA, Verheul J, et al: Treatment of nonfunctional pituitary adenoma postoperative remnants: adjuvant or delayed Gamma Knife radiosurgery? World Neurosurg 100:361-368, 2017

17. Sheehan JP, Starke RM, Mathieu D, Young B, Sneed PK, Chiang VL, et al: Gamma Knife radiosurgery for the management of nonfunctioning pituitary adenomas: a multicenter study. J Neurosurg 119:446-456, 2013

18. Swords FM, Monson JP, Besser GM, Chew SL, Drake WM, Grossman AB, et al: Gamma knife radiosurgery: a safe and effective salvage treatment for pituitary tumours not controlled despite conventional radiotherapy. Eur J Endocrinol 161:819-828, 2009

19. Tsang RW, Brierley JD, Panzarella T, Gospodarowicz MK, Sutcliffe SB, Simpson WJ: Radiation therapy for pituitary adenoma: treatment outcome and prognostic factors. Int J Radiat Oncol Biol Phys 30:557-565, 1994

20. Vladyka V, Liscák R, Novotný J Jr, Marek J, Jezková J: Radiation tolerance of functioning pituitary tissue in gamma knife surgery for pituitary adenomas. Neurosurgery 52:309-317, 2003

21. Xu Z, Lee Vance M, Schlesinger D, Sheehan JP: Hypopitu- itarism after stereotactic radiosurgery for pituitary adenomas. Neurosurgery 72:630-637, 636-637, 2013

\section{Disclosures}

The authors have reported no conflict of interest concerning the materials or methods used in this study or the findings specified in this paper.

\section{Author Contributions}

Conception and design: JH Chang, Oh, Moon. Acquisition of data: Oh, Sung, Moon, EH Kim, WS Chang, Jung, JW Chang, Park, SH Kim. Analysis and interpretation of data: JH Chang, Oh Drafting the article: JH Chang, Oh. Critically revising the article: JH Chang, Oh. Approved the final version of the manuscript on behalf of all authors: JH Chang. Statistical analysis: Oh. Study supervision: JH Chang, Oh.

\section{Supplemental Information}

\section{Previous Presentations}

The abstract of this manuscript was accepted for the 19th Leksell Gamma Knife Society 2018 Meeting, Dubai, and was in the form of oral presentation.

\section{Correspondence}

Jong Hee Chang: Brain Tumor Center, Yonsei University College of Medicine, Seoul, Korea. changjh@yuhs.ac. 